\title{
Кристаллическая структура минералов группы трифилина из сподуменовых пегматитов Колмозерского месторождения, Кольский полуостров
}

\author{
Золотарев А.А. (мл.) ${ }^{1}$, Кудряшов Н.М. ${ }^{2}$, Селиванова Е.А. ${ }^{2,3}$, Савченко Е.Э. ${ }^{2,3}$, Лялина Л.М. ${ }^{2}$ \\ ${ }^{1}$ Санкт-Петербургскийгосударственныйуниверситет, Институт науко Земле, Санкт-Петербург, \\ aazolotarev@gmail.com \\ ${ }^{2}$ Геологический институт КНЦ РАН, Anamumbl,nik@geoksc.apatity.ru; lialina@geoksc.apatity.ru \\ ${ }^{3}$ Центр наноматериаловедения ФИЦ КНЦ РАН, Anamumbl, selivanova@geoksc.apatity.ru; \\ evsav@geoksc.apatity.ru
}

Аннотация. Методом монокристалльной рентгеновской дифракции исследованы кристаллические структуры минералов группы трифилина из сподуменовых пегматитов Колмозерского месторождения, Кольский полуостров. Макроскопически различные по цвету образцы (светлые, бурые, черные) по данным микрозондового анализа образцы характеризуются различными Fe/Mn отношениями. Результаты монокристальных исследований указывают на различное заполнение позиции лития и, соответственно, на разное содержание трех- и двухвалентных катионов железа и марганца. Кристаллические структуры образцов оливинового типа уточнены в пространственной группе Рbnm с параметрами элементарных ячеек $a=4.7262(9), \mathrm{b}=10.416(2)$, $\mathrm{c}=6.070(1) \AA$ для светлой, $a=4.7813(6), \mathrm{b}=10.261(1), \mathrm{c}=6.0253(8) \AA$ для бурой, $a=4.802(6), \mathrm{b}=10.153(12)$, $\mathrm{c}=5.955(7) \AA \AA$ для черной разновидности.

Ключевые слова: фосфаты, группа трифилина, кристаллическая структура, литиофилит, сиклерит.

\section{The crystal structure of the triphylite group minerals from spodumene pegmatites of the Kolmozero deposit (Kola Peninsula)}

Zolotarev A.A. (jr) ${ }^{1}$, Kudryashov N.M. ${ }^{2}$, Selivanova E.A. ${ }^{2,3}$, Savchenko Ye.E. ${ }^{2,3}$, Lyalina L.M. ${ }^{2}$

${ }^{1}$ Saint Petersburg state University, Institute of Earth Sciences, Saint Petersburg, aazolotarev@gmail.com

${ }^{2}$ Geological Institute of Kola Science Centre of RAS, Apatity,nik@geoksc.apatity.ru; lialina@geoksc.apatity.ru

${ }^{3}$ Nanomaterials Research Center KSC RAS, Apatity, selivanova@geoksc.apatity.ru; evsav@geoksc.apatity.ru

\begin{abstract}
Crystal structures of minerals of the triphylite group from spodumene pegmatites of the Kolmozero deposit, Kola Peninsula, have been studied using the monocrystal X-ray diffraction method. Samples, in which colour differences (light, brown, black) can be observed macroscopically, are characterised by various Fe/Mn ratios after the microprobe analysis. Results of the monocrystal studies indicate a various filling of lithium position and varying contents of tri- and divalent cations of iron and manganese, respectively. Crystal olivine-type structures have been refined in the Pbnm space group, where parameters of unit cells are $a=4.7262(9), \mathrm{b}=10.416(2), \mathrm{c}=6.070(1) \AA$ for light, $a=4.7813(6), \mathrm{b}=10.261(1), \mathrm{c}=6.0253(8) \AA$ for brown, $a=4.802(6), \mathrm{b}=10.153(12), \mathrm{c}=5.955(7) \AA$ for black varieties.
\end{abstract}

Key words: phosphate, lithiophilite, sicklerite, triphylite group, crystal structure.

\section{Введение}

Минералы занимают центральное место в современном материаловедении, ориентированном на поиск материалов, способствующих технологическим прорывам во многих областях, в том числе в области устойчивого производства и хранения энергии: материалы для солнечных элементов, батарей, топливных элементов и супермагнитные материалы. Именно минералы являются источником вдохновения в этих поисках.

Исследование тонких особенностей кристаллической структуры фосфатных минералов из группы трифилина $\mathrm{LiFe}^{2+} \mathrm{PO}_{4}$, соединений, аналоги которых являются распространенным катодным материалом для литий-ионных батарей, оказывается в этой ситуации как нельзя более своевременными. Параллельно с этим решается важнейшая задача точного установления минерального вида, которая представляет определенную трудность для минералов этой группы. 


\section{Материалы и методы}

Для исследования были взяты три выборки образцов трифилина из сподуменовых пегматитов Колмозерского месторождения, Кольский полуостров, имеющих разный мотив порошковой рентгенограммы и характерные особенности морфологии, анатомии, физических свойств и химического состава. Образцы названы по макроскопически наблюдаемому цвету:

- светлый - прозрачные серо-зеленые или желтоватые зерна,

- бурый - зерна разных оттенков коричневого,

- черный - близкие к бурому, темно-коричневые до черного зерна.

Химический состав образцов определен на микрозондовом анализаторе Cameca MS-46 при ускоряющем напряжении $22 \mathrm{kV}$, токе электронного зонда 20-40 нА; с использованием следующих веществ сравнения (в скобках - аналитические линии): волластонит ( $\mathrm{Si} K \alpha, \mathrm{CaK \alpha}$ ), лоренценит $(\mathrm{Na} K \alpha)$, гематит $\left(\mathrm{Fe} K \alpha_{1}\right), \mathrm{MnCO}_{3}\left(\mathrm{Mn} K \alpha_{1}\right)$, сфалерит $(\mathrm{Zn} K \alpha 1)$, форстерит $(\mathrm{Mg} K \alpha)$, апатит $(\mathrm{P} K \alpha 1)$, $\mathrm{Y}_{3} \mathrm{Al}_{5} \mathrm{O}_{12}(\mathrm{Al} K \alpha)$.

Монокристальная съемка образцов проводилась в ресурсном центре «Рентгенодифракционные методы исследования» СПбГУ на дифрактометре Bruker Kappa Apex DUO, оснащенного плоским детектором отраженных рентгеновских лучей типа $\mathrm{CCD}$, с использованием монохроматического МоК $\alpha$ излучения ( $\lambda=0.71073 \AA)$. Интенсивности были скорректированы с использованием программного обеспечения Bruker APEX2 (Bruker-AXS, 2014). Поправка на поглощение была введена полуэмпирически, основываясь на интенсивностях эквивалентных отражений (SADABS, Sheldrick, 2007). Структуры были решены в пространственной группе Pbnm используя программу SHELX (Sheldrick, 2015), встроенную в оболочку Olex2 (Dolomanov et al., 2009). Кристаллографические данные и параметры уточнения представлены в таблице 1. Окончательные структурные модели включают в себя координаты и анизотропные тепловые параметры для всех атомов (табл. 2 и 3 соответственно). Основные межатомные расстояния ( $\AA$ представлены в таблице 4.

\section{Результаты и обсуждение}

Эмпирические формулы образцов, рассчитанные на основе $(\mathrm{P}+\mathrm{Si}+\mathrm{Al})=1$, принимая весь $\mathrm{Mn}$ и Fе двухвалентными:

$$
\begin{aligned}
& \text { бурый - }\left(\mathrm{Li} \mathrm{Na}_{\mathrm{x}} \mathrm{Na}_{\text {0-0.01 }}\right)\left(\mathrm{Mn}_{0.58-0.77} \mathrm{Fe}_{0.26-0.43} \mathrm{Zn}_{0-0.03} \mathrm{Mg}_{0-0.02} \mathrm{Ca}_{0-0.01}\right)_{0.99-1.18}\left(\mathrm{P}_{0.99-1.00} \mathrm{Si}_{\text {0-0.01 }}\right)_{1.00} \\
& \text { черный - }\left(\mathrm{Li}_{\mathrm{x}} \mathrm{Na}_{0-0.01}\right)\left(\mathrm{Mn}_{0.50-0.56} \mathrm{Fe}_{0.47-0.54} \mathrm{Mg}_{0.01-0.02} \mathrm{Ca}_{0.01-0.03}\right)_{1.01-1.10}\left(\mathrm{P}_{0.94-1.00} \mathrm{Si}_{0-0.05} \mathrm{Al}_{0-0.01}\right)_{1.0}
\end{aligned}
$$

показывают, что образцы занимают промежуточное положение между Mn- и Fe- доминантными видами группы трифилина.

Кристаллические структуры фосфатов ряда литиофилит $\mathrm{LiMn}^{2+} \mathrm{PO}_{4}-$ сиклерит $\mathrm{Li}_{1-\mathrm{x}}\left(\mathrm{Mn}^{3+} \mathrm{Mn}^{2+}{ }_{1-\mathrm{x}}\right) \mathrm{PO}_{4}$ и ряда трифилин $\mathrm{LiFe}^{2+} \mathrm{PO}_{4}-$ феррисиклерит $\mathrm{Li}_{1-\mathrm{x}}\left(\mathrm{Fe}^{3+}, \mathrm{Mn}^{2+}\right) \mathrm{PO}_{4}$ имеют много общего с постройками оливинового типа (Якубович и др., 1977).

В основе кристаллической структуры указанных минералов лежат слои из октаэдров $\mathrm{Mn} / \mathrm{Fe}(\mathrm{Mn}+\mathrm{Fe}$ - позиция M2) в плоскости (010) (рис. 1). Вдоль направления $b$ слои соединяются друг с другом через тетраэдры $\mathrm{PO}_{4}$. В свою очередь октаэдры Li (позиция M1), coединяясь через общие ребра с друг другом, образуют цепочки, вытянутые вдоль направления $c$, которые заполняют пространство между слоями из октаэдров $M 2$ (рис. 1).

Согласно структурным данным светлый образец трифилина имеет формулу $\mathrm{Li}_{0.91}\left(M^{2+}{ }_{0.91} M^{\beta+}{ }_{0.09}\right) \mathrm{PO}_{4}$; бурый образец $-\mathrm{Li}_{0.63}\left(M^{2+}{ }_{0.63} M^{3+}{ }_{0.37}\right) \mathrm{PO}_{4}$; черный $-\mathrm{Li}_{0.42}\left(M^{3+}{ }_{0.58} M^{2+}{ }_{0.42}\right)$ $\mathrm{PO}_{4}$, где $M=\mathrm{Fe}+\mathrm{Mn}$ (табл. 2). Следует отметить, что настолько низкое, как в черном образце, содержание Li в позиции M1 и преобладание трехвалентных катионов в позиции M2 ранее было известно лишь для феррисиклерита (Alberti, 1976).

Для изученных трех выборок образцов хорошо прослеживаются кристаллохимические особенности минералов группы трифилина, которые были подробно рассмотрены ра 
Таблица 1. Кристаллографические данные и параметры уточнения.

Table 1. Crystal data and structure refinement parameters.

\begin{tabular}{|c|c|c|c|}
\hline Образец & Светлый & Бурый & Черный \\
\hline Пр. гр. & Pbnm & Pbnm & Pbnm \\
\hline$a, \AA$ & $4.7262(9)$ & $4.7813(6)$ & $4.802(6)$ \\
\hline$b, \AA$ & $10.416(2)$ & $10.2605(13)$ & $10.153(12)$ \\
\hline$c, \AA$ & $6.0696(12)$ & $6.0253(8)$ & $5.955(7)$ \\
\hline$V, \AA^{3}$ & $298.80(10)$ & $295.59(7)$ & $290.3(6)$ \\
\hline $\mathrm{Z}$ & 4 & 4 & 4 \\
\hline$\rho_{\text {calc }}\left(\mathrm{M \Gamma} / \mathrm{MM}^{3}\right)$ & 3.473 & 3.468 & 3.496 \\
\hline Коэффициент поглощения (мм $\left.{ }^{-1}\right)$ & 4.768 & 4.819 & 4.906 \\
\hline $\mathrm{F}(000)$ & 299.0 & 296.0 & 293.0 \\
\hline Диапозон значений $2 \Theta,^{\circ}$ & 7.826-69.96 & 7.944-69.988 & $8.028-69.704$ \\
\hline Диапазон значений h, k, 1 & $\begin{array}{l}-7 \leq \mathrm{h} \leq 7,-11 \leq \mathrm{k} \leq 16 \\
-9 \leq 1 \leq 9\end{array}$ & $\begin{array}{l}-7 \leq \mathrm{h} \leq 6,-8 \leq \mathrm{k} \leq 16 \\
-9 \leq 1 \leq 9\end{array}$ & $\begin{array}{l}-5 \leq \mathrm{h} \leq 7,-16 \leq \mathrm{k} \leq 7 \\
-9 \leq 1 \leq 7\end{array}$ \\
\hline Всего рефлексов & 2422 & 2822 & 1935 \\
\hline Всего независимых рефлексов & $\begin{array}{l}695[\text { Rint }=0.0218 \\
\text { Rsigma }=0.0225]\end{array}$ & $\begin{array}{l}692[\mathrm{Rint}=0.0167, \\
\text { Rsigma }=0.0148]\end{array}$ & $\begin{array}{l}650[\text { Rint }=0.0215, \\
\text { Rsigma }=0.0262]\end{array}$ \\
\hline $\begin{array}{l}\text { Данные/фиксированные } \\
\text { параметры/уточняемые параметры }\end{array}$ & $695 / 0 / 41$ & $692 / 0 / 41$ & $650 / 0 / 41$ \\
\hline $\mathrm{S}$ & 1.074 & 1.153 & 1.091 \\
\hline $\mathrm{R} 1[\mathrm{I}>=2 \sigma(\mathrm{I})], \mathrm{wR} 2[\mathrm{I}>=2 \sigma(\mathrm{I})]$ & $\begin{array}{l}\mathrm{R} 1=0.0206 \\
\mathrm{wR} 2=0.0515\end{array}$ & $\begin{array}{l}\mathrm{R} 1=0.0170 \\
\mathrm{wR} 2=0.0477\end{array}$ & $\begin{array}{l}\mathrm{R} 1=0.0250 \\
\mathrm{wR} 2=0.0611\end{array}$ \\
\hline R1, wR2 (по всем данным) & $\begin{array}{l}\mathrm{R} 1=0.0247 \\
\mathrm{wR} 2=0.0527\end{array}$ & $\begin{array}{l}\mathrm{R} 1=0.0194 \\
\mathrm{wR} 2=0.0487\end{array}$ & $\begin{array}{l}\mathrm{R} 1=0.0338 \\
\mathrm{wR} 2=0.0654\end{array}$ \\
\hline $\begin{array}{l}\text { Максимальный и минимальный } \\
\text { пики на разностной карте элек- } \\
\text { тронной плотности, е } \AA^{-3}\end{array}$ & $0.59 /-0.56$ & $0.44 /-0.47$ & $0.59 /-0.80$ \\
\hline
\end{tabular}

неe (Hatert et al., 2012; Losey et al., 2004). Главные особенности связаны с процессами окисления и с одновременным выщелачиванием лития, в ходе которых минералы ряда трифилин $\mathrm{LiFe}^{2+} \mathrm{PO}_{4}$ - литиофилит $\mathrm{LiMn}^{2+} \mathrm{PO}_{4}$ в ходе окисления переходят в минералы ряда сиклерита $\mathrm{Li}_{1-\mathrm{x}}\left(\mathrm{Mn}^{3+} \mathrm{Mn}^{2+}{ }_{1-\mathrm{x}}\right) \mathrm{PO}_{4}-$ феррисиклерит $\mathrm{Li}_{1-\mathrm{x}}\left(\mathrm{Fe}^{3+}{ }_{\mathrm{x}} \mathrm{Fe}^{2+}{ }_{1-\mathrm{x}}\right) \mathrm{PO}_{4}$ по следующей схеме: $\mathrm{Li}^{+}+\mathrm{Fe}^{2+}\left(\mathrm{Mn}^{2+}\right) \rightarrow \square+\mathrm{Fe}^{3+}\left(\mathrm{Mn}^{3+}\right)$. Процесс окисления минералов сопровождается изменением цвета - от почти бесцветного (с двухвалентными катионами в позиции M2) до черного (с трехвалентными катионами в позиции $M 2$ ). С процессами окисления также связано изменение длин связей в октаэдрах и перераспределение локального баланса валентностей: происходит уменьшение средней длины связи M2-О (табл. 4) и увеличение M1-О (что коррелирует с уменьшением количества Li в этой позиции). Ранее также было показано, что в ряду трифилин - литиофилит происходит изменение параметров элементарной ячейки связанное с разными ионными радиусами $\mathrm{Fe}$ и $\mathrm{Mn}$ : параметры элементарной ячейки увеличиваются с уменьшением доли железа (Fransolet et. al., 1984). Для минералов ряда литиофилит - сиклерит также получена строгая корреляция параметров элементарной ячейки с содержанием Li (табл. 1 и 2): отрицательная для параметра $a$ и положительная для параметров $b$ и $c$. 
Таблица 2. Координаты, заселенности и эквивалентные тепловые параметры атомов.

Table 2. Fractional coordinates, occupancies and equivalent displacement parameters for atoms.

\begin{tabular}{|c|c|c|c|c|c|}
\hline Атом & $\mathrm{x}$ & $\mathrm{y}$ & $\mathrm{z}$ & Заселенность & $\mathrm{U}(\mathrm{eq}), \AA^{2 *} 10^{3}$ \\
\hline \multicolumn{6}{|c|}{ Светлый } \\
\hline LiM1 & 0 & 0 & 0 & $\mathrm{Li}_{0.91}$ & $17(1)$ \\
\hline $\mathrm{Mn} M 2$ & $0.97283(6)$ & $0.28190(3)$ & 0.2500 & $\mathrm{Mn}^{*}$ & $7.84(8)$ \\
\hline $\mathrm{P}$ & $0.41233(9)$ & $0.09331(5)$ & 0.2500 & $\mathrm{P}$ & 7.1(1) \\
\hline $\mathrm{O} 1$ & $0.7342(3)$ & $0.0968(1)$ & 0.2500 & $\mathrm{O}$ & $10.6(3)$ \\
\hline $\mathrm{O} 2$ & $0.2088(3)$ & $0.4563(1)$ & 0.2500 & $\mathrm{O}$ & $10.2(3)$ \\
\hline $\mathrm{O} 3$ & $0.2799(2)$ & $0.1630(1)$ & $0.0486(2)$ & $\mathrm{O}$ & $10.4(2)$ \\
\hline \multicolumn{6}{|c|}{ Бурый } \\
\hline LiM1 & 0 & 0 & 0 & $\mathrm{Li}_{0.63}$ & $21(2)$ \\
\hline $\mathrm{Mn} M 2$ & $0.96945(6)$ & $0.28052(2)$ & 0.2500 & $\mathrm{Mn}^{*}$ & $9.90(8)$ \\
\hline $\mathrm{P}$ & $0.41239(9)$ & $0.09504(4)$ & 0.2500 & $\mathrm{P}$ & $9.44(9)$ \\
\hline $\mathrm{O} 1$ & $0.7284(3)$ & $0.1057(1)$ & 0.2500 & $\mathrm{O}$ & $16.8(2)$ \\
\hline $\mathrm{O} 2$ & $0.1911(3)$ & $0.4545(1)$ & 0.2500 & $\mathrm{O}$ & $15.6(2)$ \\
\hline $\mathrm{O} 3$ & $0.2749(2)$ & $0.1660(9)$ & $0.0489(1)$ & $\mathrm{O}$ & $16.1(2)$ \\
\hline \multicolumn{6}{|c|}{ Черный } \\
\hline LiM1 & 0 & 0 & 0 & $\mathrm{Li}_{0.42}$ & 19(4) \\
\hline $\mathrm{Mn} M 2$ & $0.96739(8)$ & $0.27939(4)$ & 0.2500 & $\mathrm{Mn}^{*}$ & $10.7(1)$ \\
\hline $\mathrm{P}$ & $0.4129(1)$ & $0.9596(6)$ & 0.2500 & $\mathrm{P}$ & $10.7(1)$ \\
\hline $\mathrm{O} 1$ & $0.7268(4)$ & $0.1110(2)$ & 0.2500 & $\mathrm{O}$ & $18.3(4)$ \\
\hline $\mathrm{O} 2$ & $0.1800(4)$ & $0.4524(2)$ & 0.2500 & $\mathrm{O}$ & $17.0(4)$ \\
\hline $\mathrm{O} 3$ & $0.2724(3)$ & $0.1680(1)$ & $0.0484(2)$ & $\mathrm{O}$ & $17.5(3)$ \\
\hline
\end{tabular}

*смешанная $\mathrm{Mn}-\mathrm{Fe}$ позиция.

Таблица 3. Анизотропные тепловые параметры для атомов $\left(\AA^{2} \times 10^{3}\right)$.

Table 1. Anisotropic displacement parameters $\left(\AA^{2} \times 10^{3}\right)$ for atoms.

\begin{tabular}{|c|c|c|c|c|c|c|}
\hline Атом & $\mathrm{U}_{11}$ & $\mathrm{U}_{22}$ & $\mathrm{U}_{33}$ & $\mathrm{U}_{23}$ & $\mathrm{U}_{13}$ & $\mathrm{U}_{12}$ \\
\hline \multicolumn{7}{|c|}{ Светлый } \\
\hline $\mathrm{Li}$ & $15(2)$ & 21(3) & $16(2)$ & $-2.5(16)$ & $-5.2(15)$ & $-3.8(14)$ \\
\hline $\mathrm{Mn}$ & $8.68(12)$ & $7.62(14)$ & $7.21(14)$ & 0 & 0 & $0.44(9)$ \\
\hline $\mathrm{P}$ & $6.66(18)$ & $7.4(2)$ & $7.3(2)$ & 0 & 0 & $0.10(15)$ \\
\hline $\mathrm{O} 1$ & $5.9(5)$ & $12.5(7)$ & $13.4(7)$ & 0 & 0 & $0.0(4)$ \\
\hline $\mathrm{O} 2$ & $9.4(5)$ & $7.6(6)$ & $13.7(7)$ & 0 & 0 & $0.8(5)$ \\
\hline $\mathrm{O} 3$ & $9.9(4)$ & $12.8(5)$ & $8.5(4)$ & 2.2(4) & $0.1(3)$ & $1.7(3)$ \\
\hline \multicolumn{7}{|c|}{ Бурый } \\
\hline $\mathrm{Li}$ & 16(3) & $18(3)$ & $29(3)$ & $-3(2)$ & $-8(2)$ & $-2.9(18)$ \\
\hline $\mathrm{Mn}$ & $10.11(13)$ & $9.51(12)$ & $10.09(11)$ & 0 & 0 & $-0.58(7)$ \\
\hline$P$ & $7.87(19)$ & $9.90(17)$ & $10.56(16)$ & 0 & 0 & $-0.05(13)$ \\
\hline $\mathrm{O} 1$ & $8.5(6)$ & $23.1(6)$ & $18.7(5)$ & 0 & 0 & $0.5(4)$ \\
\hline $\mathrm{O} 2$ & $18.6(6)$ & $11.5(5)$ & $16.6(5)$ & 0 & 0 & $1.4(4)$ \\
\hline $\mathrm{O} 3$ & 14.3(4) & $18.5(4)$ & 15.4(4) & 4.1(3) & $-1.7(3)$ & $1.4(3)$ \\
\hline \multicolumn{7}{|c|}{ Черный } \\
\hline $\mathrm{Li}$ & $16(6)$ & $9(5)$ & $31(7)$ & $-7(5)$ & $-10(5)$ & $-4(4)$ \\
\hline $\mathrm{Mn}$ & $9.74(18)$ & $11.75(17)$ & $10.57(17)$ & 0 & 0 & $-0.85(13)$ \\
\hline $\mathrm{P}$ & $8.6(3)$ & 11.7(3) & 11.9(3) & 0 & 0 & $0.1(2)$ \\
\hline $\mathrm{O} 1$ & $8.6(8)$ & $26.1(10)$ & 20.1(9) & 0 & 0 & $0.7(7)$ \\
\hline $\mathrm{O} 2$ & 19.4(9) & $14.2(8)$ & 17.3(9) & 0 & 0 & $1.5(8)$ \\
\hline $\mathrm{O} 3$ & $14.3(6)$ & $20.8(6)$ & $17.4(6)$ & $4.2(6)$ & $-1.5(5)$ & $2.0(5)$ \\
\hline
\end{tabular}


Таблица 4. Основные межатомные расстояния $(\AA)$.

Table 4. Selected bond lengths $(\AA)$.

\begin{tabular}{|c|c|c|c|c|c|c|c|c|}
\hline \multicolumn{3}{|c|}{ Светлый } & \multicolumn{3}{|c|}{ Бурый } & \multicolumn{3}{|c|}{ Черный } \\
\hline $\mathrm{Li}-$ & $\mathrm{O} 1 \mathrm{x} 2$ & $2.213(1)$ & $\mathrm{Li}-$ & $01 \times 2$ & $2.265(1)$ & $\mathrm{Li}-$ & O1 x2 & $2.282(2)$ \\
\hline Li - & $\mathrm{O} 2 \times 2$ & $2.098(1)$ & $\mathrm{Li}-$ & $\mathrm{O} 2$ x 2 & $2.161(1)$ & $\mathrm{Li}-$ & $\mathrm{O} 2$ x2 & $2.193(2)$ \\
\hline $\mathrm{Li}$ - & $\mathrm{O} 3 \times 2$ & $2.172(1)$ & $\mathrm{Li}-$ & $\mathrm{O} 3 \times 2$ & 2.171(1) & $\mathrm{Li}-$ & $\mathrm{O} 3$ x 2 & $2.169(2)$ \\
\hline$<\mathrm{Li}$ - & $\mathrm{O}>$ & 2.161 & $<\mathrm{Li}-$ & $\mathrm{O}>$ & 2.199 & $<\mathrm{Li}-$ & $\mathrm{O}>$ & 2.215 \\
\hline Mn - & $\mathrm{O} 1$ & $2.233(1)$ & Mn - & $\mathrm{O} 1$ & $2.132(1)$ & Mn - & O1 & $2.063(3)$ \\
\hline Mn - & $\mathrm{O} 2$ & $2.132(1)$ & $\mathrm{Mn}$ - & $\mathrm{O} 2$ & $2.076(1)$ & Mn - & $\mathrm{O} 2$ & $2.032(3)$ \\
\hline Mn - & $\mathrm{O} 3 \times 2$ & $2.109(1)$ & Mn - & $\mathrm{O} 3 \times 2$ & $2.0995(9)$ & Mn - & $\mathrm{O} 3 \times 2$ & $2.078(2)$ \\
\hline Mn - & $\mathrm{O} 3 \times 2$ & $2.266(1)$ & $\mathrm{Mn}$ - & $\mathrm{O} 3 \times 2$ & $2.232(1)$ & Mn - & $\mathrm{O} 3 \times 2$ & $2.206(2)$ \\
\hline$<\mathrm{Mn}-$ & $\mathrm{O}>$ & 2.186 & $<\mathrm{Mn}-$ & $\mathrm{O}>$ & 2.145 & $<\mathrm{Mn}-$ & $\mathrm{O}>$ & 2.111 \\
\hline $\mathrm{P} \quad-$ & $\mathrm{O} 1$ & $1.522(1)$ & $\mathrm{P} \quad-$ & $\mathrm{O} 1$ & $1.515(1)$ & $\mathrm{P}$ & $\mathrm{O} 1$ & $1.515(3)$ \\
\hline $\mathrm{P} \quad-$ & $\mathrm{O} 2$ & $1.538(1)$ & $\mathrm{P} \quad-$ & $\mathrm{O} 2$ & $1.524(1)$ & $\mathrm{P} \quad-$ & $\mathrm{O} 2$ & $1.524(3)$ \\
\hline $\mathrm{P} \quad-$ & $\mathrm{O} 3 \times 2$ & $1.553(1)$ & $\mathrm{P} \quad-$ & $\mathrm{O} 3 \times 2$ & $1.5596(9)$ & $\mathrm{P} \quad-$ & $\mathrm{O} 3 \times 2$ & $1.559(2)$ \\
\hline <P - & $\mathrm{O}>$ & 1.542 & $<\mathrm{P}-$ & $\mathrm{O}>$ & 1.540 & $<\mathrm{P}-$ & $\mathrm{O}>$ & 1.539 \\
\hline
\end{tabular}

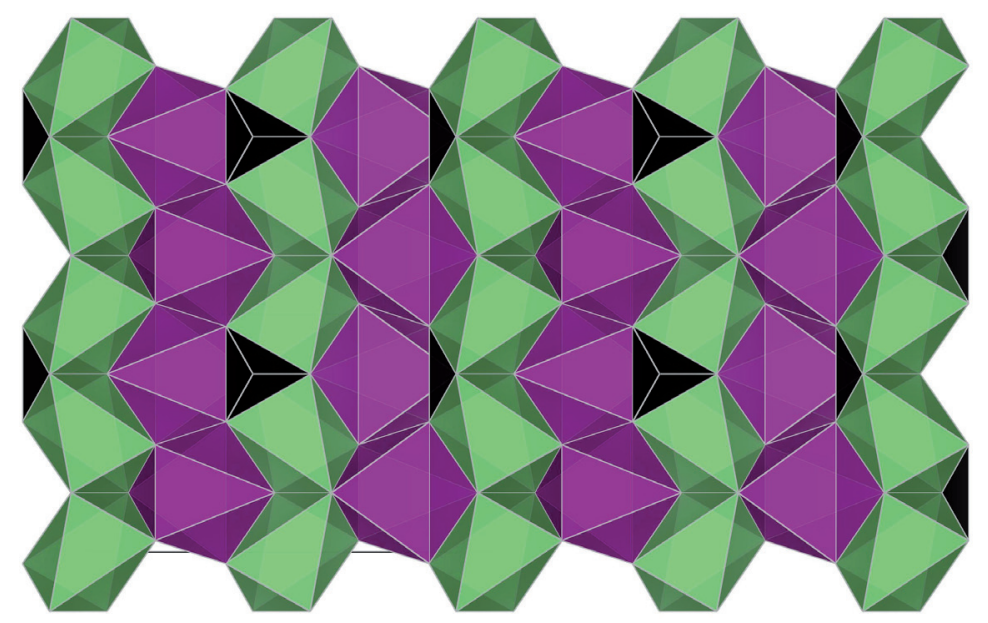

Рис. 1. Кристаллическая структура минералов ряда литиофилит - сиклерит: проекция на плоскость $b c$. Фиолетовым цветом обозначены октаэдры $(\mathrm{Mn}+\mathrm{Fe}) \mathrm{O}_{6}$, черным - тетраэдры $\mathrm{PO}_{4}$, зеленым - октаэдры $\mathrm{LiO}_{6}$.

Fig. 1. The crystal structure of mineral of the lithiophilite - sicklerite series: projection to the $a b$ plane. The $(\mathrm{Mn}+\mathrm{Fe}) \mathrm{O}_{6}$ octahedra are violet, $\mathrm{PO}_{4}$ tetrahedra are black, the $\mathrm{LiO}_{6}$ octahedra are green.

Кроме того, более высокое содержание Fе в черной разновидности коррелирует с более высокой степенью окисленности этого образца, по сравнению с бурой высокомарганцевой разновидностью. Данный факт требует серьезных исследований механизмов окисления минералов группы трифилина из сподуменовых пегматитов Колмозерского месторождения.

Работа выполнена в рамках темы НИР №0226-2019-0051 и поддержана грантом Президента РФ для ведущих научных школ НШ-2526.2020.5 .

\section{Литература}

1. Якубович О.В., Симонов М.А., Белов Н.В. Кристаллическая структура синтетического трифилина $\mathrm{LiFe}\left[\mathrm{PO}_{4}\right] / /$ ДАН СCCР. 1977. 235. 1. С. 93-95.

2. Alberti A. The crystal structure of ferrisicklerite, $\mathrm{Li}_{<1}\left(\mathrm{Fe}^{3+}, \mathrm{Mn}^{2+}\right) \mathrm{PO}_{4} / /$ Acta Crystallogr. 1976. B32. P. 2761-2764.

3. Bruker-AXS. APEX2; Version 2014.11-0; Bruker-AXS: Madison, WI, USA, 2014. 
4. Dolomanov O.V., Bourhis L.J., Gildea R.J., Howard J.A.K., Puschmann H. OLEX2: A complete structure solution, refinement and analysis program // J. Appl. Crystallogr. 2009. 42. P. 339-341.

5. Fransolet A-M., Antenucci D., Speetjens J-M., Tarte P. An X-ray determinative method for the divalent cation ratio in the triphylite-lithiophilite series // Mineral Mag. 1984. 48. P. 373-381.

6. Hatert F., Ottolini L., Wouters J., Fontan F. A structural study of the lithiophilite-sicklerite series // The Canadian Mineralogist. 2012. 50. P. 843-854.

7. Losey A., Rakovan J., Hughes J.M., Francis C.A., Dyar M.D. Structural variation in the lithiophilite-triphylite series and other olivine-group structures // The Canadian Mineralogist. 2004. V. 42. P. 1105-1115.

8. Sheldrick G.M. SADABS; University of Goettingen: Goettingen, Germany, 2007.

9. Sheldrick G.M. Crystal structure refinement with SHELXL // Acta Crystallogr. 2015. V. C71. P. 3-8. 